Jeffrey Klenotic

\title{
Mapping Flat, Deep, and Slow: On the 'Spirit of Place' in New Cinema History
}

\begin{abstract}
This essay engages in a creative, heuristic, and reflexive consideration of the 'localities' of cinema audiences by exploring New Cinema History as a place. New Cinema History is conceptualised as a place continually produced in and through its interactions with the heterogeneous multiplicities of situated audiences and experiences of cinema that form the topoi of its landscape of inquiry. In reflecting on how this placialised landscape has been and might be represented, I argue that New Cinema History's 'spirit of place' is most productive when rendered within a 'splatial' framework that draws upon practices of flat, deep, and slow mapping to offer new possibilities for bridging space and place, narrative and cartography, and history and geography. These practices motivate myriad forms of collaboration and data exchange among diverse projects and stakeholders that perforate and continually redraw boundaries of knowledge using dynamic, multiple, open tactics for representing and recombining research.
\end{abstract}

\section{Keywords}

Place; space; cinema audiences; flat maps; deep maps; slow maps; GIS

\section{Introduction}

[T] he very formation of the identity of a place - its social structure, its political character, its 'local' culture - is also a product of interactions. (...) The global is in the local in the very process of the formation of the local.

-Doreen Massey

A place is something for which we continually have to discover or invent new forms of understanding, new concepts in the literal sense of ways of 'grasping-together'. A place is more an event than a thing to be assimilated to known categories. As an event, it is unique, idiolocal.

-Edward S. Casey 


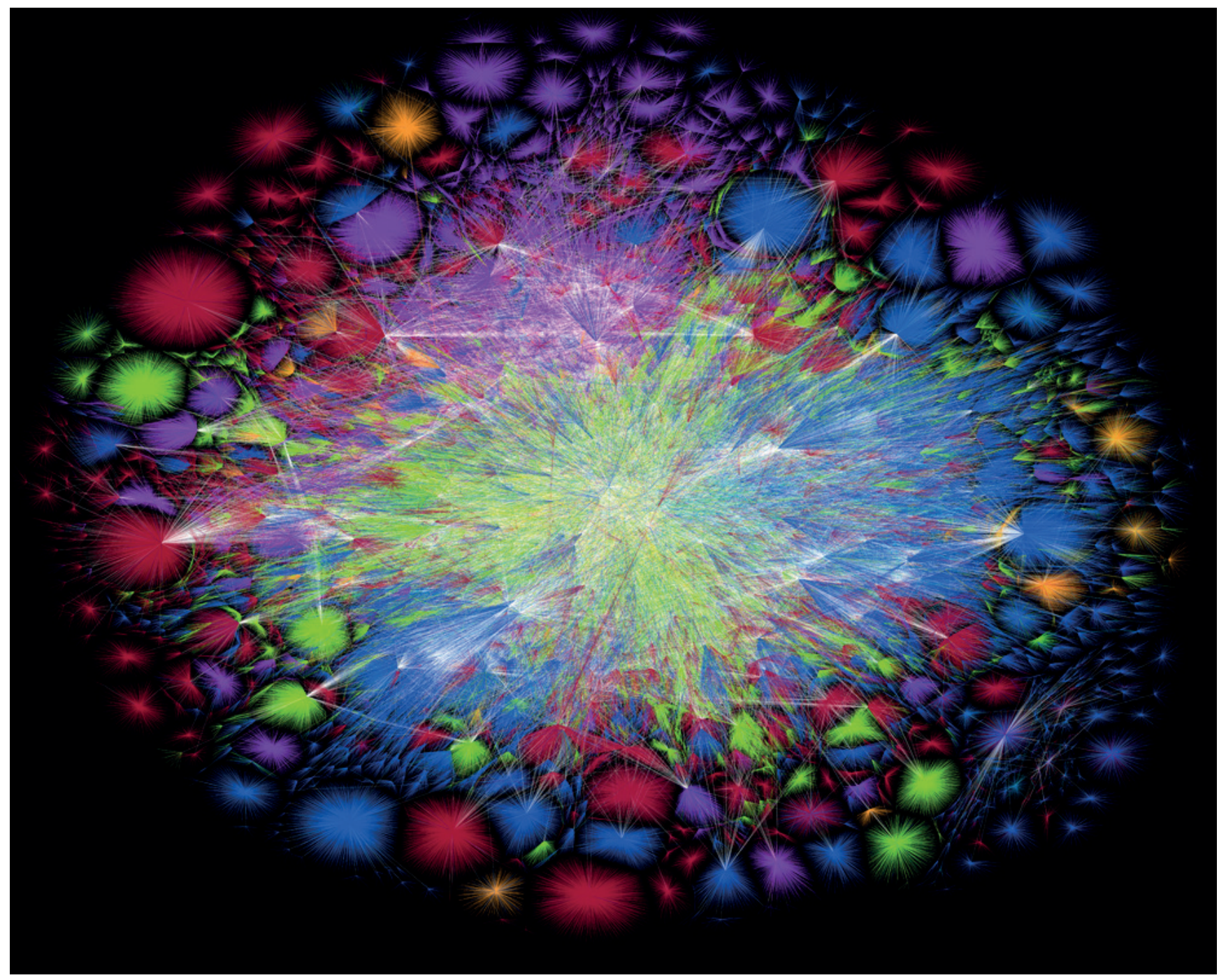

A map of the internet in 2014 by Barrett Lyon and the OPTE project. Source: https://web.archive.org/ web/20181228014321/http:/www.opte.org/.

This issue's call for papers announced its interest in comparative histories on the 'localities' of cinema audiences by highlighting the contributions that synchronic and diachronic comparisons of particular places make to 'a distinct understanding of larger film exhibition patterns and trends, to identify what is specifically local, differentiated from what is more general. ${ }^{1}$ The call noted the value that such audience and exhibition studies had for 'New Cinema History' especially, and it 
foregrounded several modes and locations of inquiry that were identified with the ethos of this body of work:

This special issue aims to encourage comparative and collaborative scholarship. In the spirit of New Cinema History, we welcome papers from disciplines beyond history and film studies. We also seek to include work in underexplored global regions like South America, Africa, and Asia. $^{2}$ (italics added)

To summon the 'spirit of place,' philosopher Edward S. Casey argues, is to call forth 'the insurrectional power of place,' and 'like the congeneric terms soul and feeling, spirit signifies that which refuses to submit to dichotomizing. ${ }^{3}$ It is the 'spirit' of place that 'sweeps the binarism of Self and Other (... ) into the embracing folds, the literal im-plications, of implacement. Such a spirit (...) submerges all the established metaphysical limits and many of the physical borders as well. ${ }^{4}$ In the following reflection, invited by the issue's editors, I seek to engage in a creative, heuristic, and reflexive consideration of the 'localities' theme by exploring New Cinema History itself as a place. I hope to show that New Cinema History can be understood as a place continually produced, conceptually and empirically, in and through manifold interactions with heterogeneous multiplicities of situated audiences and grounded experiences of cinema that comprise its field of study. ${ }^{5}$ These interactions are inscribed by geographic, ethnographic, historiographic, and cartographic practices of placialisation that reconstitute and reconfigure past places of moviegoing and everyday life in the present. As a place of/for placial inscriptions, New Cinema History is distinguished by an amorphous and decentred landscape of inquiry where porous disciplinary boundaries, open networks of connection and collaboration, methodological eclecticism, and diverse, contingent territorialisations yield 'knowledge that is rigorous, yet resists grand narrative and remains open to revision and to multiple perspectives and interpretations. ${ }^{6}$ It is in this landscape's very immanence, its fecundity for polyvocal and multilayered place-making, its hospitality for the commonality of placial difference and multiple becoming, that I believe we find what $T M G$ refers to in its call as the 'spirit of New Cinema History.'

I will begin by locating the placiality of New Cinema History on both conceptual and empirical grounds. Toward this end, New Cinema History will be situated in a broader phenomenological 
framework as well as in a narrower historical account of its origins and development. I then reflect on how New Cinema History's 'spirit,' understood not as a reified research approach but as an affective marker of New Cinema History's landscape of inquiry as a place, has been and might be manifested. This includes consideration of the prospects for comparative research, which I modestly caution against framing as 'an essential part of a discipline's strategy to become methodologically more mature. ${ }^{7}$ As an alternative, I argue that New Cinema History's 'spirit of place' is most distinct, dynamic, and productive when it taps the 'insurrectional power' indwelling in the experience of cinema, where centripetal forces meet centrifugal tendencies, and tactical connections can be formed to destabilise centre/margin relations. From this starting point, comparing the practices of film audiences and exhibitions in particular localities is framed not as a strategic disciplinary step toward methodological maturity, but as part of the vitalising contribution that New Cinema History can make to what Selina Springett describes as an essential democratising 'trend in ontological practices of connectivity and subsequent epistemological "flattening” of knowledge. ${ }^{8}$ Here I argue that by flattening the map of New Cinema History, we may discover new possibilities for bridging the divides between space and place, narrative and cartography, and history and geography. ${ }^{9}$ To do so would be to move toward what Shih-Lung Shaw and Daniel Sui call a 'splatial' framework, ${ }^{10}$ one that incorporates 'the multiple dimensions of both space and place' so as to better develop 'linkages between the absolute, relative, relational, and mental' intensities of human dynamics. ${ }^{11}$ Such a framework connects New Cinema History to the idea that space is less a general nesting environment for carving out specific places that can be statically compared than a field of flux produced in and through the very event of 'placialisation'. Space is an inseparable part of what Edward Casey calls an 'indefinite dyad' with place, a 'twoness' that 'is not that of two things, or even of two of a kind, but instead that of two quite variant kinds - which nevertheless coexist in all their disparity and cannot seem to do otherwise. ${ }^{12}$ As Casey puts it, 'the ultimate source of spatial selfproliferation is not the body or the way the world is but the placialisation of space itself. (...) [T] he distinction between space and place is not derivative but generative.'13 Conceived 'splatially,' the key outcomes of comparison spring less from its disciplinary ethos than from its capacity to generate the proliferation of collaboration and data exchange among diverse projects and stakeholders so as to emplace and submerge closed, strategic modes of publication that bifurcate research (finished/unfinished, published/unpublished, professional/amateur) within dynamic, multiple, open tactics for representing and recombining research. These tactics can put vernacular 
forms ${ }^{14}$ of deep mapping ${ }^{15}$ and slow mapping ${ }^{16}$ in conversation with more conventional Geographic Information System (GIS) practices of placialisation, making New Cinema History a prime locus for innovative historiographical practices in the context of what Shelley Fisher Fishkin calls 'Digital Palimpsest Mapping Projects'. ${ }^{17}$

\section{Groundwork for the 'spirit of place' in New Cinema History}

The ontological ground for the epistemological topography that emerges from the landscape of New Cinema History that I am drawing here can be summarily gleaned by combining insights from my epigraphs by Doreen Massey ${ }^{18}$ and Edward Casey. ${ }^{19}$ If the "very formation of the identity of a place its social structure, its political character, its “local” culture' - is 'a product of interactions' that weave local to global and continually gather in/to a place, then any sense of place formed from these interactions is an 'event' always made anew. This is true wherever that event occurs in time-space, as any place of re-collection is pulled into relation with the place(s) re-collected, contributing to its product of interactions. It is also the case that any affect, meaning, or perception bound up in the identity of a place is the 'product of interactions' as well. The productivity of place is a dynamic, multiplicative process, not a static, additive one. Place is irreducible to the sum of the parts that make up its interactions (if such a total reconstruction were somehow possible), and depending on which parts of these interactions are 'grasped together' and multiplied, any identity, affect, perception, and meaning attached to place will multiply as well. To bring knowledge and intelligence, broadly defined, of/from a place into being is to continually discover or invent new forms of understanding.

From this phenomenological perspective, New Cinema History as a place is a continuous, heterogeneous event of re/discovering, re/inventing, and re/inscribing the past as a product of re/ collected interactions relating to experiences of place. In this, New Cinema History is like all forms of historical inquiry. As historian Philip J. Ethington puts it, history begins in the understanding that,

Every past is a place (emphatically in the present tense because the past is always present). All action and experience takes place, in the sense that it requires place as a prerequisite, and makes place, in the sense of inscription. (...) I propose that we refer to the places of the past as topoi. ${ }^{20}$ 
While New Cinema History shares in the common trajectory of all studies of the past, what distinguishes it are its topoi. As objects of study, the 'pasts' gathered to New Cinema History are formed in and through multiplicities of places where myriad experiences of movies gathered as complex products of interactions on local and global trajectories. These experiences intersected with the diverse, continual place-making events of audiences who may (or may not) have come to understand the localities of these interactions as gathering places with distinct identities. The wider social relations and spatial configurations re/produced in and through these interactions and intersections of people, places, and things are also pasts that gather to New Cinema History. Formed in and through its topoi, New Cinema History is, too, a topos; it is a place gathering experiences, the product of interactions, and a gathering place for multiplicities of inscriptions. It is a locus for intersecting past trajectories to be emplaced in the present to produce space for the future. It is a locus of 'becoming,' in a Deleuzian sense, where there is 'affirmation of the positivity of difference,' and 'teleological order and fixed identities are relinquished in favour of a flux of multiple becoming. ${ }^{21}$

This conceptualisation of New Cinema History as place can be moved to firmer ground by situating it in a more embodied and historically specific set of trajectories relating to the field's origins and development. In 2011, with publication of Explorations in New Cinema History: Approaches and Case Studies, New Cinema History became widely visible as a scholarly topos through the careful articulation of a discourse that inscribed it as a fully established area of research that had 'achieved critical mass and methodological maturity' and developed a 'distinct identity' built upon the 'circulation and consumption' of films and the examination of cinema as 'a site of social and cultural exchange. ${ }^{22}$ As Biltereyst, Maltby and Meers have noted, however, the term New Cinema History itself had originated less formally several years earlier in 2007 at the 'The Glow in Their Eyes: Global Perspectives on Film Cultures, Film Exhibition and Cinemagoing' conference in Ghent, Belgium. ${ }^{23}$ And while the term may have emerged in 2007, its emergence, much like any rising neologism, did not mark the start of the 'spirit' of that which it came to signify and summon. Rather, the surfacing of New Cinema History as a neologism was a decisive moment in the trajectory of a discourse, the indexical sign of an intellectual movement that had already gathered much energy and momentum. While the 'audience turn' in film history had been developing since at least the $1990 \mathrm{~s},{ }^{24}$ the specific exigency and concrete locus of multiple becomings for the discourse later known as New Cinema History arguably dated to 2003. That was when a small group of scholars from varying social, 
academic, and geographic locations were serendipitously gathered into a rhetorical commonplace (what might film history become if it engaged more fully with the histories of movie audiences?) by a palpable if yet unnamed zeitgeist of possibilities that permeated the 'American Cinema and Everyday Life' conference held at University College London. A year later in June 2004 that 'global' contingent of scholars produced its first 'local' place, a two-day working group event organised and chaired by Arthur Knight at the College of William and Mary's Washington, D.C. offices. ${ }^{25}$

The impetus for the meeting was to collectively imagine a plan for sustaining and expanding the development of historical audience studies and contextualised exhibition and programming databases such as those presented at 'American Cinema and Everyday Life' (a selection of this work is found in Going to the Movies: Hollywood and the Social Experience of Cinema). ${ }^{26}$ Concerned that such research could be marginalised as too local, extradisciplinary, and empirical (or even mistaken as empiricist) in relation to text-centred narratives of film history and film theory, the group envisioned an international initiative that could become a multi-disciplinary framework for a decentred approach to the study of film and cinema cultures 'from below' using audience-oriented, bottom-up modes of research. ${ }^{27}$ It was hoped that accumulating case studies could offer a wellspring for empirically grounded, middle-range theories to explain cinema's role as a spatially uneven and highly variable social and cultural institution imbricated in wider and longer term processes such as modernisation, assimilation, globalisation, consumerism, and economic consolidation. The global scope of such an initiative would require scholarly collaboration and methodological resourcefulness because it could proceed only through piecemeal studies that recovered fragmentary traces of diverse, ephemeral film audiences situated by social, cultural, political, economic, and geographic relations that shaped how cinema practices were embedded (or not) in particular communities.

In 2004, an expanding (but still very limited) range of digitised historical records and primary source materials, along with growing access to research computing tools, geospatial mapping applications, and the (pre-smartphone, pre-social) World Wide Web, seemed to offer a potential research infrastructure and networking platform for the emerging initiative, which required new methods and approaches for collecting, sharing, analysing, and exploring historical data internationally. The use of such resources, however, would depend on technical skills, which spurred individual professional development and collaboration with scholars in disciplines such as computer science, information technology, library and information science, and geography, among others. 
The Dutch Cinema Context Collection (CCC) was one prominent example of digital cinema history that gathered to the locus of the working group at that time. It afforded online access to a comprehensive relational database of local cinema data on a national scale, stirring insights into the 'DNA of Dutch film culture.'28 The CCC offered a fully conceptualised database model that the working group considered and drew upon as it contemplated metadata standards and cinema data collection schema that might be used globally across local, regional, national, and international case studies and databases to make them interoperable. The working group was also locus for the Williamsburg Theater Project (WTP), which demonstrated the active role that undergraduate students could play in collecting cinema data from digitised newspapers. The WTP offered 'a portrait of moviegoing - and of cultural life more generally in the "Colonial Capital" [of] Williamsburg, Virginia, USA, ${ }^{29}$ and its database helped spawn case studies, such as the search for signs of African-American moviegoing in the small-town US South. ${ }^{30}$ In terms of research methods, The Enlightened City ${ }^{31}$ (EC) project on screen cultures in Antwerp and Ghent, Belgium, forged rigorous protocols for triangulating historical data from oral histories, film programmes, and cinema locations that later became a model for other projects within (and beyond) the working group, while Mapping Movies (MM), which at that time was a desktop Geographic Information System (GIS) developed to explore moviegoing in New England, modelled the potential of geo-data and geo-referenced historical materials for researching cinema history. ${ }^{32}$ The group was also a locus for sharing and expanding the POPSTAT method for analysing film popularity. POPSTAT helped 'get around the problem of counting each cinema as equal by estimating a proxy measure of the relative box-office revenues earned by any one film screened among a population of cinemas. 33

Even as these projects pointed to the possibilities for inscribing the historical topoi of cinema audiences and experiences using digital computing tools, large data sets, and quantitative analyses, the working group remained a vital locus for mixed methods and was committed to the core practice of qualitative case studies. Such microhistories plumbed the depths of local cinema cultures, often using oral history and cultural ecology or cultural geography approaches to foreground overlooked or marginalised audiences and communities of cinema, such as work on rural cultures in Australia, ${ }^{34}$ or studies of urban working class cultures in Springfield, Massachusetts. ${ }^{35}$

Many goals emerged from the meeting, but top among them were to advance the use of digitised historical records and expand the gathering of oral histories to foster diverse case studies 
of film audiences, exhibition sites, programming practices, and cinema cultures on a global scale; to utilise digital mapping tools and cross-searchable databases to enable comparative research and data exchange; and to develop web portals and online platforms to spur collaboration and engage students and the public in long-term cinema history, collective memory, and community research projects.

Before adjourning, the working group considered what to call the new initiative. Several options were narrowed to the International Cinema Audiences Research Group (ICARG) and the History of Moviegoing, Exhibition and Reception Project (HoMER Project). In part, the two names foregrounded different modes of interaction harboured by the multiplicity of elements that formed the initiative's vision of 'disseminating new models of collaborative research. ${ }^{36}$ On one hand, the initiative sought to become a locus for the 'collection, scholarly vetting, and sharing, via the world wide web of new data on film going, exhibition, and reception. 37 This implied a 'group' that could exercise a measure of editorial, curatorial, and administrative oversight over the network as a whole, but also in terms of supporting the development of grant proposals and project outcomes relating to delimited collaborative research efforts. On the other hand, the initiative also envisioned a 'portal website that brings these new datasets together and, ideally, makes them cross searchable. ${ }^{38}$ This implied collaboration in and through an online 'project' that would become a place for gathering data and historical materials as well as a place where users could gather to explore and remix data, and make serendipitous discoveries. Thought was also given to combining the choices into the International Cinema Audience Research Group's HoMER Project. For several years after the working group meeting, all three names were used at one time or another in differing contexts and various forms of communication, but eventually the HoMER Project settled into place as the primary name for the initiative.

Membership in the HoMER Project increased steadily from the very beginning. Group interaction grew dynamically larger and productively more diverse, generating a proliferation of case studies spanning an increasingly wide range of historical eras and geographical localities. Two electronic seminars $(2006,2014)$ on the social history of cinemagoing were organised for a global population of graduate students, and HoMER members participated in online class discussions. ${ }^{39}$ Research methods and data protocols once relatively uncommon for studying historical movie audiences and cinema cultures - oral histories, digitised newspapers, census data, POPSTAT, GIS 
mapping, triangulation, and more - were shared widely and used more systematically across a range of scales. A Delphi study was done to explore the development of a common vocabulary and schema to enable interoperability among a growing number of HoMER research projects. ${ }^{40}$ Grant funding for collaborative research on the history of cinemagoing in relation to cultural heritage, cultural database development, generational memory, and the curation of online archival resources increased dramatically, particularly outside the United States. Planning meetings, research workshops, and conferences became annual or semi-annual events, in localities such as London, Amsterdam, Ghent, Chapel Hill, Wollongong, Adelaide, and Prague. Most were stand-alone meetings, but over time they increasingly intersected with the trajectories of larger conferences such as those hosted by the European Network for Cinema and Media Studies (NECS) or (less frequently) the Society for Cinema and Media Studies (SCMS). HoMER meetings were buttressed through the development of a website and email listserv open to anyone who wanted communications. It was in this flux of multiple becomings that Explorations in New Cinema History staked its claim, in 2011, that 'this collection launches the "New Cinema History"' and it 'would not have been possible without the inspiration of an international group of scholars in the History of Moviegoing, Exhibition, and Reception (HOMER) project, chaired by Arthur Knight..41

As the vitality of HoMER as a locus for group interactions and experiences was energised and expanded during this period, the potential for project interaction among an increasingly heterogeneous array of unique studies built organically from the ground up became technologically and logistically challenging to realise. These challenges were further complicated by difficulties finding multinational funding that could be used to develop stable, sustainable, open-ended, web platforms that lowered access barriers for global research and data exchange beyond the remit of individually funded project teams and targeted outputs for research and tool development. The goal of fully interoperable projects became less of a focus for group interactions, and in 2014 the HoMER Project was renamed the HoMER Network. ${ }^{42}$ This signalled a durable commitment to annual research gatherings that expanded knowledge and facilitated the collaborative publication of edited anthologies and special journal issues related to the field of New Cinema History. These events gathered new experiences and interactions in/to HoMER and contributed to the production of a concrete sense of place for New Cinema History. Within this locus, the zeitgeist channelled by HoMER could be 'grasped together' with the discourse of New Cinema History to produce a new concept, the 'spirit of New Cinema History.' 


\section{Flattening comparisons in New Cinema History}

Since 2014, comparative research such as that called for by this issue of $T M G$ has become one of several trajectories of discourse and clusters of interaction gathering in/to New Cinema History. ${ }^{43}$ Daniel Biltereyst and Philippe Meers, for example, have offered a carefully developed and judicious assessment of the many challenges and opportunities for comparative research in the field of New Cinema History. They describe in depth and detail four 'modes or sensibilities of comparison' that afford different foundations for cinema research going forward. ${ }^{44}$ These range from informal and inductive types of 'amorphous' comparison across studies that make use of multiple methodological frames and focus on multiple places/spaces/sites (mode one), to comparative studies of a single place/ space/site using multiple methods (mode two), to comparative studies of multiple places/spaces/sites that are designed to test hypotheses using a similar methodological frame (mode three), to replication studies where the same methodological frame is applied to the same place/space/site by different researchers (mode four). Across all modes, they find two main approaches are taken to facilitate research: One

is the close collaboration between researchers (...) and the development of common standards across the projects. Another is the development of online databases, (...) or the use of software which enables researchers to cross-search those data sets, along with digital tools that can share and contextualize it all. ${ }^{45}$

Imagining how the four modes might map the highly diverse landscape produced by over a decade's work of New Cinema Histories, Biltereyst and Meers acknowledge that

this methodological heterogeneity does not offer an ideal platform for comparison, [but] we would like to argue that even those studies that were not conceived to be integrated into a comparative set-up (can) provide interesting insights for understanding dis/similarities in cinema cultures, as much as they might be helpful in recognising particular recurrent patterns and conditions influencing them. ${ }^{46}$

The paths leading through these comparative modes of research are in some respects paths that turn and loop back in attempt to regrasp and reconnect with the earlier trajectory of activities that had 
been launched by the vision of fully interoperable projects that had once attached to the HoMER Project. Comparative mode one, for example, has strong echoes of the original working group's vision of a 'portal website that brings these new datasets together and, ideally, makes them cross searchable. ${ }^{47}$ But the comparative turn has also been framed less as a reconnection than an intervention of sorts, an essential part of 'a discipline’s strategy to become methodologically more mature. ${ }^{38}$ As such, it has been seen as a cartographic remedy for a 'diagnosis on geographical monocentrism (...) within the New Cinema History perspective, ${ }^{49}$ a logical next step forward to scale up and methodologically harmonise 'monocentric' microhistories that focus narrowly on 'local practices and experiences, often concentrating on film exhibition and audience experiences in particular cities, neighbourhoods or venues. ${ }^{50}$

Here I offer a modest caution, as such a 'diagnosis' risks framing microhistories as methodologically immature and incapable of connecting or analysing macro patterns and forces as they operate in micro places. This positions microhistories as but first steps in the direction of comparative studies where 'linking cinema cultures in two or more different geographical and/or temporal contexts' is argued to 'entail methodological sophistication. ${ }^{51}$ Such a sequential, striated path from cases to comparisons, however, may unduly stratify local and global forces and relations, prioritising space over place rather than insisting on their interaction at all scales of experience and historical analysis. As the anthropologist Clifford Geertz argued many years ago in The Interpretation of Cultures, the production of local 'peculiarities' in specific places may itself be key to the general spatial pattern of all human cultural experience:

Becoming human is becoming individual, and we become individual under the guidance of cultural patterns (...) and the cultural patterns are not general but specific. (...) This (...) is what we really have in common. ${ }^{52}$

For Geertz, 'the road to the general, to the revelatory simplicities of science, lies through a concern with the particular, the circumstantial, the concrete. ${ }^{53}$

Another concern that may flow from a sequential view of methods for New Cinema History is that in addition to positioning microhistory as the first step on an epistemological ladder, it points that ladder in the direction of 'methodological maturity' as the telos of New Cinema History. This might be analogous to viewing early cinema history as a sequence of distinctly local start-up 
exhibition sites emerging, merging, and fading on a linear trajectory en route to the institutional maturity and sophisticated business methods of the integrated movie palace era. It has of course been precisely through the centrifugal force created by the sheer diversity of New Cinema History's micro studies that such accounts of exhibition have become increasingly contested and difficult to sustain, opening up new horizons for a people's history of cinema. ${ }^{54}$ We should remember, moreover, that in 2011, Explorations in New Cinema History declared itself already as the culmination of a body of research that had reached 'methodological maturity." 55 To position comparative studies as now a step toward even 'more mature' methods en route to disciplinarity opens a rhetorical door to escalating calls for ever greater levels of methodological sophistication at larger scales of geography. Such calls would tilt to quantitative methods, perhaps culminating in New Cinema Histories powered by automation and big data. This could skew research toward audiences and experiences that left the most traces in the historical record, and discourage exploration of cinema's role in relation to audiences who were embedded in social and spatial processes of marginalisation or exclusion. We may then find the end of a teleological road that turns us back looking for monocentric remedies to a diagnosis of geographical omnivision.

Certainly, as Mary Beth Haralovich observes, 'the detailed “microhistory” necessary for understanding everyday life must also be integrated into the greater dynamics of social processes. ${ }^{56}$ Judith Thissen similarly argues that microhistories of movie audiences and cinema cultures can make greater or lesser contributions to an understanding of wider historical trends and patterns, depending on the scope of their questions, the rigor of their research, and the strength of their engagements with larger explanatory frameworks and interrelated objects of study from multiple disciplines. ${ }^{57}$ She also notes that 'comparative history combines very well with the idea of microhistory,' particularly in 'small-scale comparison[s] ... that make connections between particular circumstances and developments,' so the two methods are not mutually exclusive..$^{58}$

To strengthen its relevance for broader debates, New Cinema History must continue to inspire research that pushes and crosses the boundaries of historical thought through the formulation of insightful arguments stimulated by resourceful methods. But the epistemological risks of a methodological maturity discourse may outweigh the benefits if it has the unintended consequence of inviting a teleological and centripetal narrative that centres New Cinema History on methods, rather than aligning it with the decentred geohistory of billions of cinema experiences that are at the ontological heart of its object of study. After fifteen years of very productive research since the 
HoMER Project began, we have barely scratched the surface in exploring the breadth and depth of that field of inquiry. Comparative research has much to contribute, as does research at larger scales of spatial and social analysis. But we also need countless more microhistories than we now have to connect to and perhaps vex work at other scales. This is arguably as true for Australia, Europe, and North America, where much work has been located, as it is for 'underexplored global regions like South America, Africa, and Asia,' as called for by TMG. Moreover, this doesn't even begin to count recent experiences of cinema created by

new technologies of representation, reproduction, display, sharing, and distribution (...) [that have] exploded the once at least theoretically delimitable spaces of moviegoing into an as yet literally unrepresentable heterogeneous multiplicity. ${ }^{59}$

It also doesn't begin to count the re-discoveries and re-inventions that may be produced for places/ events that have already been explored. As Richard Abel reminds us, 'much of what we often think of as old, overly familiar, and so widely assumed can always be excavated, reexamined and viewed anew. Is the past ever really past?'60

In offering these reflections on possible unintended consequences of a discourse of methodological maturity in New Cinema History, I do not wish to devalue comparative research. On the contrary, the comparative sensibility described by Biltereyst and Meers, as previously discussed, is careful and judicious in addressing problems and limitations of comparative research, as well as its opportunities:

We hope to have indicated that comparison is more than the orthodox version of it, and that the comparative mode or sensibility should cultivate the idea that we need to look at cinema both from a close and a distant perspective. ${ }^{61}$

Rather than discouraging comparison, I would instead like to reposition it from a methodological or disciplinary advance to an important part of the contribution that New Cinema History can make to a democratising 'trend in ontological practices of connectivity and subsequent epistemological “flattening” of knowledge.'62 
Here we might think of comparison as part of a 'splatial' turn that, following Shaw and Sui, would seek to map and understand the myriad ways in which 'physical and virtual, objective and subjective, territorial and topological worlds are (...) coupled and entangled for most human activities from local to global scales. ${ }^{33}$ As Edward Casey puts it, 'space is a doublet composed of itself (whatever that is) and place' and 'we continually find ourselves immersed in a multiplex spatial network whose nodal points are supplied by particular places. If space is infinitely large, place is indefinitely many. ${ }^{64}$ Just as place and space can be conceived as an inseparable doublet, close and distant perspectives on nodes in the multiplex can also be taken as a doublet. Moreover, rather than analytically forcing close and distant views apart so as to sort them into a sequence or hierarchy of perspectives (such that close views may show local specificities of place before ceding to distant views that reveal general spatial patterns), we might instead try to hold close and distant views together as simultaneous perspectives. Selina Springett, building upon the work of Bruno Latour, argues that the process of 'mapping ontologies of connections and flattened epistemes' requires that 'micro should be examined alongside the macro, rather than as existing "above" or "below."'65 Flattening the epistemological landscape in this way 'involves slowing the investigative process down so as to trace the connections, which may have been previously considered "micro" to that which is "macro." ${ }^{66}$ For Springett, the slow process of inquiry necessary to explore simultaneous perspectives in detail to discover their multitudinous connections mitigates confusions of scale and limits assumptions about causality prompted by vertical frames that spur cognitive leaps about micro practices being 'nested' in macro contexts.

As a rudimentary example, consider a hypothetical mobile app that accompanies its users as they walk through a Paramount movie palace built in the 1920s. The app augments the experience with voluminous layers of self-selectable imagery from Paramount-owned theatres in other locations from the same era. Walking slowly through the Paramount while examining images from other theatres in the company's chain of roughly 1200 theatres in the US and Canada, it becomes possible for diverse app users to compare local elements proximate to their own bodies (nearby seats, stage, balcony, people, etcetera) with local elements proximate to bodies elsewhere (pictures of seats, stage, balcony, people, etcetera). The grasping together of these connections of here and there, near and far, into diverse, unique assemblages of elements can produce understandings of the theatre that mitigate a nested perspective of seeing it primarily as a localised version of general socio-spatial patterns or as a microcosm of the Paramount theatre chain as a whole. 
A 'splatial' perspective is comparative, but it seeks to avoid striating space and place. Instead, it keeps place open as a locus of multiple becoming, similar to Deleuze and Guattari's conceptualisation of the local absolute as 'an absolute that is manifested locally, and engendered in a series of local operations of varying orientations' that are taken in particular places. ${ }^{67}$ These places simultaneously exist in a realm of 'smooth space' that is 'precisely the space of the smallest deviations: therefore, it has no homogeneity, except between infinitely proximate points, and the linking of proximities is effected independently of any determined path.' 68 To discover, for example, that Paramount's theatres had only white men in managerial positions would not end in an explanation that the theatres were nested in a general company policy of sexism and racism that played out locally along a linear, predetermined, spatially and placially invariable path. Instead, it might go further to explore how ideologies of sexism and racism were re/produced nonlinearly in and through the simultaneous operations of diverse, embodied, locally variable orientations and experiences. Here, power would not simply travel from space to place to be delivered locally. Instead, it would have to be enacted place by place, time after time, in twelve hundred heterogeneous multiplicities assembled into a constellation that formed an ordered whole of difference structured in dominance by a power geometry that created social and ideological proximities among spatially distant places. If one or more places within this constellation resisted by placing a woman of colour into management, this might open up the possibilities for new tactical connections being formed to places in different constellations, producing different, more progressive power geometries. As Doreen Massey reminds us, 'the global is in the local in the very process of the formation of the local, ${ }^{, 69}$ and sorting out how power operates in that 'doublet' in a way that accounts for structure but at the same time preserves the latent capacity for agency and becoming requires a blended mix of methods and perspectives.

\section{Mapping the landscape of New Cinema History}

Springett's view of flattened epistemes that map ontological connections between places dovetails with Philip Ethington's argument that all historical interpretation is a form of mapping: 
It matters that history takes and makes place because knowing the topoi of history is literally to map the human past. (...) Maps represent the relationships among topoi, be they points, lines, polygons, or actions, events, experiences, and ideas. ${ }^{70}$

The resulting 'cartography’s infinitely possible figurations cannot be reduced to [a single, comprehensive] narrative form. ${ }^{71}$

In New Cinema History, the potential for mapping 'flat' has loomed large from the very start. Maps have been seen figuratively and literally as well-suited for the unique challenges posed by the spatial and social complexity of cinema experiences. As Robert Allen argued in his seminal essay on the place of space in cinema history,

The local places of moviegoing (...) need to be re-presented not as autonomous, neutral, static places that contain audiences and movies, and that then can be 'compared' to other such places somewhere else, but as internally heterogeneous nodal points in a social, economic, and cultural cartography of cinema: intersections of overlapping trajectories, networks, trails, and pathways, whose identities are constructed through the connections and collisions that occur there. ${ }^{72}$

Recently, Allen has also pointed to the role that digital maps can play in mitigating confusions of scale arising from historiographical practices that tend to cultivate an undue separation of micro and macro frames of reference:

Google Maps help us a lot by providing a spatial correlative to a conceptual remapping of the relationship of things relevant to cinema going on somewhere at some time. We need a historiography that is zoomable, that can zoom to a high degree of granularity, but we operate with the recognition that when we do zoom in to that high degree of granularity, and it fills the screen as it were, it's obscuring a whole lot of other things. We then also need to be able to zoom out, and to be able to connect. Not the small with the large, but here with the there. ${ }^{73}$ 
By flattening micro and macro perspectives, the aim is not to remove cartographic relief or ignore the unevenness and distinct contours of the landscape, but rather to start the analysis from the assumption of endless splatial variability and then move to discover and explore concatenations of practices and experiences as they crossed social categories and migrated through the pores of geographic boundaries. Allen argues that we should seek out such connections between places as they developed in the becoming, rather than rear-projecting some basis for comparison using preformed sociocultural-geographic categories (e.g. urban, rural) or assumptions that a given place is comprised of a fixed collection of internal attributes that make it comparable (or not) with some other place. ${ }^{74}$ Taking note of the rapid digitisation of historical newspapers around the world, Allen observes that this will soon mean, for example, that

we no longer have to constitute Antwerp as the place, the thing that we compare to someplace else, but we will be able to see the variety and differences that may create new connections that we couldn't see before, but also help us to resist the temptation to reduce Antwerp to Antwerp. ${ }^{75}$

In tracing practices of movie exhibitions and audiences through digitised newspapers (looking for practices where they are found instead of finding them only where we think to look), Allen suggests we may identify combinations and permutations in assemblages of elements that shaped experiences of cinema. Mapping relationships and trajectories of elements within and among these multiplicities might then aid our understanding of how idiolocal experiences of cinema connected (or disconnected, excluded, and marginalised) places, people, and objects in one locality to places, people, and objects in another. ${ }^{76}$

Discovering connections among historical topoi does, to some extent, mean the resulting maps, though flattened, remain the product of empirical observations of events. These observations may come from newspapers, trade papers, historical maps, memories, postcards, photographs, films, etc., but at some place in time they must be locatable to be mapped. Ethington writes that, 'history is a map of the past, but that map is not merely a representation. Topoi touch the ground in myriad ways (...) [and] are not free-floating signifiers. ${ }^{77}$ A map, however, need not imply a singular or fixed territorialisation, one that denies differences or ambiguities of perspective about where events touched ground, or that closes the flux of multiple becomings by imposing positivistic, imperialistic, or colonialist perspectives. The history of cartography itself supports Ethington's argument that all history is a form of mapping, and 
he notes that 'cartography is not inherently flawed because of its reinvention during the imperial epoch of the European Renaissance. The critique of Eurocentric, scientific space is an instance of perspectivalism,' and 'perspective itself now must be subjected to critique of its grounded metaphoricality in order to understand subject positions as topoi that can be mapped. ${ }^{78}$

A flattened map also does not preclude depth in the layers of subjectivity, affect, interpretation, and perspective that can be brought to the topography and topology of the landscape of inquiry. Springett argues, 'to flatten the landscape or to render it flat in order to begin to understand the topography (...) does not necessarily imply an elimination of depth, but rather a democratization of knowledge. ${ }^{79}$ For Springett, the practices of placialisation best suited to a flattened landscape are actually those associated with 'deep’ mapping, which spatial humanities scholar David Bodenhamer conceptualises as an effort to 'understand space and place as the product of interrelationships, coexistence, and process, always changing and always in the state of becoming. ${ }^{80}$ Bodenhamer, John Corrigan and Trevor Harris argue that methodologically,

Deep maps are not confined to the tangible or material, but include the discursive and ideological dimensions of place, the dreams, hopes, and fears of residents - they are, in short, positioned between matter and meaning. ${ }^{81}$

While deep maps embrace longstanding methods and practices of thick description, they go further to embed these within 'a finely detailed, multimedia depiction of a place' that 'is simultaneously a platform, a process, and a product. ${ }^{92}$ Rather than being fixed and filtered in and through the univocal discourses of historians, artists, and anthropologists, Springett calls for deep maps that make 'a concerted effort to (...) seek out multiple voices connected to place' such that the map 'becomes an enaction of place. ${ }^{83}$ This effort is crucial for cinema history, as Kate Bowles notes, because

the idiosyncratic nature of cinema attendance' is what makes it 'such a valuable lens on social history; each cinema audience consists of individuals who have made their way somewhat independently to the movie theater on time (or not) through a maze of sociohistorical circumstances. (...) To understand the social narratives by which communities, families, or individuals came to value or disparage cinema in particular historical contexts, we need to design research that is open to the collection of stories. ${ }^{84}$ 
As polyvocal enactions of place, deeps maps afford a representational environment that is highly amenable to stories. These would not be mustered to support a singular argument, but instead would be framed, as David Bodenhamer writes, 'as a conversation and not a statement' ${ }^{55}$ so as to 'encourage multiplicity, competing perspectives, and alternate worldviews. ${ }^{96}$

Within New Cinema History, innovative work in this direction comes from the Italian Cinema Audiences project, which has used deep mapping practices to explore emotional geographies and memories of cinemagoing during the $1950 \mathrm{~s} .{ }^{87}$ This work not only maps a multitude of audience surveys and recorded interviews to collect diverse stories, cultivate diverse connections, and create diverse conversations about cinema history, it also facilitates intergenerational mapping projects that enable younger and older citizens with diverse worldviews to develop connections and conversations through cinema history. ${ }^{88}$ In this, the Italian Cinema Audiences project realises the potential of New Cinema History both as a 'place gathering' knowledge about the topoi of cinema’s past, and as a 'gathering place' or topos that itself is 'democratically positioning existent past, present and future knowledge and, thereby, building a structure of connectedness. 89

The performative dimensions of deep mapping permit diverse practices of representation and creativity. These include conventional elements of cartography and placial inscription (points, lines, polygons, thematic maps, time sliders, animations, scale bars, legends, etcetera), but also audio, video, poetry, photography, hyperlinks, memory, georeferenced archival documents, map annotations, and augmented or virtual reality, to list only a few possibilities for introducing 'ambiguity, complexity, nuance, and plurality' into the map. ${ }^{90}$ Les Roberts argues that assemblages cobbled in deep maps reflect 'spatial bricolage as an interdisciplinary (or "undisciplined") nexus of practices and pick-and-mix methods' with 'creative expression in the art and poetics of "making do." 91 He draws from Claude Levi-Strauss to describe the researcher as a bricoleur who 'speaks not only with things (...) but also through the medium of things. ${ }^{92}$ Corey Sparks argues similarly about digital humanities in general, theorising it as 'speculative art' that 'warps linear perspective' using 'technical apparatus, scientific examination, and artistic endeavor. ${ }^{93}$ The Kinomatics Project, which explores intersections of New Cinema History, the creative industries, digital humanities, and big data, has been particularly innovative in pushing the limits for representing cultural and historical data spatially, visually, and aurally. ${ }^{94}$

When maps go flatter and deeper, they must also go slower. This is partly because, as Springett observes, flat ontologies and deep maps demand 'an unhurried investigation' to enact a densely 
polyvocal sense of the 'multitudinous exchanges' and relationships that occur in and among places. ${ }^{95}$ The aim is not to narrow the experience of maps to the cognitive instrumentalism of a fastest route through space or infographic version of place, but to 'present place as always open to the addition of supplementary voices. ${ }^{96}$ Like the places and connections it inscribes, a slow map is an ongoing event. Over time, the map grows ever denser in the interactions of voices, perspectives, and information that gather in/to it, and the intelligence, insight, and knowledge yielded as products of those interactions multiply and grow iteratively more nuanced and complex.

I have experienced slow mapping first hand through my efforts to use Geographic Information System (GIS) software to discover and explore landscapes of cinema history. The project, Mapping Movies, is still unfolding seventeen years after it began. It started as a simple attempt to better understand places of moviegoing in one small city during the first few decades of the twentieth century by 'animating' social data attached to a map of the city's neighbourhoods discovered in a book published in 1926. Those neighbourhoods are now layers in a flat, deep, slow web-GIS project that renders cinema and non-cinema data from many eras and spans the United States and a few countries in Europe as well. ${ }^{97}$ The project's long history inscribes it as the record of my evolving bricolage of largely self-taught, 'making-do' efforts to learn GIS to support my research, but its interactive maps also serve as resources for public and community history. While the web-GIS site allows geospatial information to be uploaded by any interested citizens and scholars, doing so requires technical training, which has lessened participation. As a result, most of the map's layers are my own creation. ${ }^{98}$ Nonetheless, the site does offer what geographer John Krygier describes as a key affordance of a Public Participatory GIS (PPGIS), which is that 'users can "make" and "un-make" information and thus shape and reshape the way they understand their neighbourhood, region, county, and the world. ${ }^{99}$ To understand place through an active process of making and unmaking information through a densely layered map interface takes time, and as critical GIS scholar Matthew Wilson observes, 'to think the map as an event is to introduce a series of pedagogical moments, to motivate a mapping that is beyond effectivity and toward affectivity.' 100 Like Edward Casey, for whom place is an event that demands we 'discover or invent new forms of understanding, new concepts, ${ }^{101}$ Wilson argues that slow maps require an 'investment of attention necessary to understand and learn about geographical relations. (...) The map, through such slow map experimentation, becomes theory in the sense of a creative conceptualisation.' ${ }^{102}$ 
For New Cinema History, maps can be slow for quite practical reasons as well. These have to do with the fact that, as Kate Bowles lucidly puts it, 'cinema research is massively unfinishable.' ${ }^{103}$ She writes,

the culture of our everyday navigations and un-self-conscious routines depends entirely on our capacity for rapid, continuous evaluation of the things we see around us, and is then expressed in all the tiny choices that we make to move in one direction or another. Seen in perspective, cinema is one small thread in the overall cultural weave. ${ }^{104}$

To take seriously the problems of scale and detail that come with any attempt to understand countless threads of cinema experiences woven into the cultural fabric at even one venue over time, let alone to imagine doing this for billions of cinema experiences in countless places across the globe, is to face certain defeat. As Bowles observes, 'The question of failure is an important one for researchers drawn to massively unfinishable historical projects' ${ }^{105}$ and 'it is this challenge that takes us into the territory of vernacular and participatory mapping. ${ }^{106}$ Noting that professional historians often evince a deep-rooted 'resistance to volunteer-contributed information' as being 'contaminated' and in need of scrubbing, Bowles argues that the impossible dream of a perfect 'map of total cinema history' should move 'closer to the realm of the Open Street Map, the ongoing social annotation of Google map data, and other massively open web-based mapping projects' that become sustainable precisely because they are 'deliberately incomplete, and this will require us to learn new modes of humility and even institutional patience in the face of what remains to be mapped.'107

Sharing historical authority with the general public may well produce maps that are unable to keep cinema in predetermined scholarly grids formed by film exhibition classifications, institutional taxonomies of audience experience, and harmonised data coding schemes. Shared historical authority may in fact lead to maps that chart the 'everyday navigations and un-self-conscious routines' of movie attendance in ways that stray from the well-worn places, networks, and pathways of a cinema-centric view of cinema history to trace idiosyncratic connections between local geography, family history, and community milieu. ${ }^{108}$ Such maps may even speak to cinema's absence, to its implication in local operations of placial exclusion, social marginalisation, and economic disinvestment. New Cinema History could be fertile ground indeed for what David Harvey calls a 'people's geography' that would be 'threaded into the fabric of daily life,' where 'ideologies and prejudices' were part of the 'complex weave of competition, struggle, and cooperation within (...) shifting social and physical landscapes.' ${ }^{109}$ 
As an unstable multiplex of professional and vernacular practices, published and unpublished research, and finished and unfinished maps, public participatory mapping projects would harbour multiple tensions. Centripetal forces would tangle with centrifugal tendencies, and tactical connections could be formed to make and unmake contingent territorialisations that rendered the landscape of inquiry, and the very object of cinema history research itself, in any number of ways. These tensions would enable diverse assemblages of voices, perspectives, objects, and information to be activated as users maneuvered the map by unleashing the push and pull energies of its myriad layers like so many hands on a planchette vying for control over the spirit board of New Cinema History. Such a map would no doubt be messy, unruly, undisciplined; it may lead those who use it to lose their way as much as find it, to end up in places they weren't looking for or never knew existed, full of questions not answers. Even so, this need not be seen as evidence of data contamination or catastrophic methodological failure. Instead, it may remind us that the function of maps is to 'begin our exploration, not to represent its conclusion' ${ }^{110}$ and to afford possibilities for engaging in both 'the linear progression we associate with rational argument and (...) the depth, texture, tension, and resonance of experience. ${ }^{111}$ At the heart of the epistemological ethos of slow mapping is a challenging journey toward theory building and creative conceptualisations of the relations between place and space. As Matthew Wilson puts it: 'Make slow maps. Tinker and fail.'112

\section{Conclusion}

In reflecting on New Cinema History as a 'locality,' I have tried to understand it as a place continually produced, conceptually and empirically, in and through its interaction with the heterogeneous multiplicities of situated audiences and grounded experiences of cinema that form the topoi for its investigations. New Cinema History is neither a passive container for research nor an actively delimited discipline. It is instead a place gathering experiences, the product of interactions, and a gathering place for scholars and citizens from many different backgrounds. It is a topos that is inscribed by diverse geographic, ethnographic, historiographic, and cartographic practices that reconstitute and reconfigure past places of moviegoing and everyday life in the present. These inscriptions, taken as a whole, amount to a collective, multiperspectival atlas of historical cinema cultures. As a place, New Cinema History has a distinct identity, one known for its decentred landscape of inquiry, bottom-up political character, and 'local' culture of open 
collaboration, multi-disciplinarity, and global networks for sharing research and exchanging data. The 'spirit' of this place is not narrowly tied to a strategic telos, internal history, or reified research approach, but is rather the dynamic and diffuse product of interactions attaching to New Cinema History as a locus for the positivity of difference and flux of multiple becomings. It is this spirit of place that is invoked in the most recent volume of inscriptions to emerge from this topos, The Routledge Companion to New Cinema History, which characterises New Cinema History as 'a movement, or a "nebula" of research seeking to understand the complexities of cinema cultures and experiences.' 113

In its conceptual and increasingly splatial propensities for flat, deep, and slow mapping practices, New Cinema History is well-placed to render its 'nebula' of research as a 'Digital Palimpsest Mapping Project' (DPMP). As described by Shelley Fisher Fishkin, DPMP’s are 'palimpsests' and not 'publications' because they 'allow multiple versions of events, of texts, of phenomena (both primary and secondary) to be written over each other - with each version still visible under the layers. ${ }^{114}$ And they are 'projects rather than products' because those enjoined in and through them are enfolded and submerged within 'open-ended, collaborative works-in-progress' 115 that by virtue of 'requiring collaboration - across borders, languages, nations, continents, and disciplines (...) bring our interdependence - as scholars, as citizens, as human beings - to the foreground. ${ }^{116}$ Inscriptions in the palimpsest 'might take a dizzying range of forms' but they would share basic features, such as a concern for topics that cross borders, an interface that included embedded links to texts and images in different locations and languages and that reflected competing or conflicting perspectives on the subject, and free accessibility to 'as broad an international public as possible' and 'hosted on openaccess university or other nonprofit websites.'117

New Cinema History already has or is actively pursuing the requisite components for a DPMP. Its nebula has gathered in/to it a thickening cloud of global research matter in the form of cases (microhistories, location data), connections (programming flows, distribution networks/circuits), comparisons (thematic maps, comparative statics), constellations (regional studies, theatre chains), conversations (oral histories, interviews), and collaborations (project teams, public partners). Along with published matter, New Cinema History also has a rapidly expanding number of online databases and projects that, if put into interaction with each other, would energise the nebula's capacity to generate diverse, new inscriptions in the digital palimpsest. ${ }^{118}$ Perhaps most importantly, in its slow but steady efforts to invite the public to take a vested, participatory interest in historical research, 
New Cinema History is laying the foundation for a DPMP that could be made sustainable. Greater public participation in New Cinema History also sets it up to meet the challenges and opportunities created by a new landscape of digital abundance, where citizens and local historians will need to be involved not only as researchers, but also because they must have an active stake in the conversation about the (de)materiality of cinemagoing heritage and the place it will occupy in how communities connect to their pasts and imagine their futures.

While New Cinema History has met many sufficient conditions for a DPMP, it has not yet met the key necessary condition, which is an online platform that enables the publics and projects of New Cinema History to gather in/to a cartographic commons. That commons could be a shared mapping website fed by a distributed global network of users who can not only visualise and interact with cinema history through maps, but also pull data and other material from these maps to generate and upload thousands of unique bricolage. If its collective matter can be shared in and through a DPMP, the nebula of New Cinema History should pulse with ever brighter inspirational and insurrectional energies. What new places might this nebula produce? What new clusters, interactions, intensities, and movements? What new questions, discoveries, explanations, and explorations? It will be in the 'spirit of New Cinema History' to work together to move research beyond the realm of fixed publication and dissemination of results and into an ever-unfinished flat, deep, and slow map for data recombination and reinscription of the past.

\section{Notes}

1 Jessica Whitehead, Thunnis van Oort and Paul Moore, "Call for Papers - Localities: Comparative Histories of Cinema Audiences TMG - Journal for Media History,” https://networks.h-net.org/node/14467/ discussions/3577101/call-papers-localities-comparative-histories-cinema-audiences-tmg. All web links cited here were last accessed September 9, 2020.

2 Whitehead, Van Oort and Moore, “Call for Papers." Unless otherwise indicated, the use of italics within any of this essay's quotations reflects their appearance in the original source(s).

3 Edward S. Casey, Getting Back Into Place: Toward a Renewed Understanding of the Place-world (Bloomington and Indianapolis: Indiana University Press, 1993), 314. 
5 For a discussion of the object of study in New Cinema History, see Robert C. Allen, "The Place of Space in Film Historiography,” Tijdschrift voor Mediageschiedenis 9, no. 2 (2006): 15-27. See also Richard Maltby and Philippe Meers, “Connections, Intermediality, and the Anti-Archive: A Conversation with Robert C. Allen” in The Routledge Companion to New Cinema History, ed. Daniel Biltereyst, Richard Maltby and Philippe Meers (London and New York: Routledge, 2019), 16-27.

6 Jeffrey Klenotic, "Putting Cinema History on the Map: Using GIS to Explore the Spatiality of Cinema," in Explorations in New Cinema History: Approaches and Case Studies, ed. Richard Maltby, Daniel Biltereyst and Philippe Meers (Malden, MA: Blackwell Publishing, 2011), 58-84, specifically 61.

7 Daniel Biltereyst and Philippe Meers, "New Cinema History and the Comparative Mode: Reflections on Comparing Historical Cinema Cultures," Alphaville Journal of Film and Screen Media 11 (2016): 13-32, specifically 25 , DOI: 10.33178 /alpha.

8 Selina Springett, “Going Deeper or Flatter: Connecting Deep Mapping, Flat Ontologies and the Democratizing of Knowledge,” Humanities 4 (2015): 623-636, specifically 625, DOI: 10.3390/h4040623.

9 For a review essay discussing these divergencies as they play out across three recent books on cinema history, see Paul S. Moore, “Space, Place, and Case: Surveying the Grounds of Cinema History,” Early Popular Visual Culture 13, no. 4 (2015): 336-343, DOI: 10.1080/17460654.2015.1096030. Alan R. H. Baker's Geography and History: Bridging the Divide (Cambridge: Cambridge University Press, 2003) offers a thorough overview of the longstanding debates between historians and geographers as well as invaluable ideas for surmounting these debates.

10 The term 'splatial' is not yet in wide use, but some work in GIScience on smart cities, as well as in geospatial humanities, has begun to elaborate it more fully into a distinct analytical framework. For example, see Shih-Lung Shaw and Daniel Sui, "Understanding the New Human Dynamics in Smart Spaces and Places: Toward a Splatial Framework," Annals of the American Association of Geographers 110, no. 2 (2020): 339-348, DOI: 10.1080/24694452.2019.1631145, and Alberto Giordano, Shih-Lung Shaw and Diana Sinton, “Guest Editors’ Introduction: The Geospatial Humanities: Transdisciplinary Opportunities," International Journal of Humanities and Arts Computing 14, no. 1/2 (2020): 1-5, DOI: 10.3366/ ijhac.2020.0241.

11 Shaw and Sui, "Understanding the New Human Dynamics," 345.

12 Edward S. Casey, "Smooth Spaces and Rough-Edged Places: The Hidden History of Place," The Review of Metaphysics 51, no. 2 (1997): 267-296, specifically 295.

13 Casey, "Smooth Spaces," 268. 
14 Kate Bowles, "Beyond the Boundary: Vernacular Mapping and the Sharing of Historical Authority," in Locating the Moving Image: New Approaches to Film and Place, ed. Julia Hallam and Les Roberts (Bloomington and Indianapolis: University of Indiana Press, 2014), 221-244.

15 Springett, “Going Deeper or Flatter.”

16 Matthew W. Wilson, New Lines: Critical GIS and the Trouble of the Map (Minneapolis: University of Minnesota Press, 2017).

17 Shelley Fisher Fishkin, “'DEEP MAPS”, A Brief for Digital Palimpsest Mapping Projects (DPMPs, or 'Deep Maps'),” Journal of Transnational American Studies 3, no. 2 (2011), Retrieved from https://escholarship.org/ uc/item/92v100t0.

18 Doreen Massey, Space, Place, and Gender (Minneapolis: University of Minnesota Press, 1994), 120.

19 Edward S. Casey, "How to Get from Space to Place in a Fairly Short Stretch of Time: Phenomenological Prolegomena," in Senses of Place, ed. Steven Feld and Keith H. Basso (Santa Fe, NM: School of American Research Press; Distributed by the University of Washington Press, 1996), 13-52, specifically 26.

20 Philip J. Ethington, “Placing the Past: 'Groundwork' for a Spatial Theory of History,” Rethinking History 11, no. 4 (2007): 465-493, specifically 483, DOI: 10.1080/13642520701645487.

21 Rosi Braidotti, “Discontinuous Becomings. Deleuze on the Becoming-Woman of Philosophy,” Journal for the British Society of Phenomenology 24, no. 1 (1993): 44-55, specifically 44, DOI: 10.1080/00071773.1993.11644270.

22 Richard Maltby, “New Cinema Histories,” Explorations in New Cinema History, 3-40, specifically 3.

23 Daniel Biltereyst, Richard Maltby and Philippe Meers, "Reflections and Comments," The Routledge Companion, 13.

24 Biltereyst, Maltby and Meers, "Reflections and Comments." My focus is narrowly on tracing the discursive emergence of New Cinema History, but research and reflection on the sociology of moviegoing and studies of historical audiences span back nearly to the medium's own emergence. Summaries and examples, from a U.S. context, are found in Garth S. Jowett, Film, The Democratic Art: A Social History of American Film (Boston, London: Focal Press, 1976), Garth S. Jowett, Ian C. Jarvie and Kathryn H. Fuller, Children and the Movies: Media Influence and the Payne Fund Controversy (Cambridge: Cambridge University Press, 1996) and Gregory A. Waller, ed., Moviegoing in America (Malden, MA: Blackwell, 2002).

25 My account of the working group meeting is based on memories, notes, emails, and early versions of the group's website hosted on a server at the College of William and Mary (http://homerproject.blogs. wm.edu/). Any errors or lacunae in the account of this event are entirely my own. Meeting attendees were 
Kate Bowles, Kathy Fuller-Seeley, Douglas Gomery, Amy Howard, Jeffrey Klenotic, Arthur Knight, Richard Maltby, Phillipe Meers, Rob Nelson, Clara Pafort-Overduin, John Sedgwick, and Robert Silberman. The initial list of interested working group participants included 26 scholars, but all were not able to attend the meeting sessions. This information is recorded in emails from Arthur Knight to the group's listserv dated 3 and 24 August 2004.

Richard Maltby, Melvyn Stokes and Robert C. Allen, eds., Going to the Movies: Hollywood and the Social Experience of Cinema (Exeter, UK: University of Exeter Press, 2007).

27 Richard Maltby, “On the Prospect of Writing Cinema History from Below,” Tijdschrift voor Mediageschiedenis 9, no. 2 (2006): 74-96; Robert C. Allen, “Relocating American Film History: The 'Problem’ of the Empirical," Cultural Studies 20, no. 1 (2006): 48-88.

28 Karel Dibbets developed the CCC project and Clara Pafort-Overduin presented it to the working group. It is online at http://www.cinemacontext.nl/.

29 Arthur Knight and Rob Nelson developed the WTP project. No longer online, early versions can be found on the Internet Archive. See, for example: https://bit.ly/2YXhXUk. See also https://wmpeople.wm.edu/site/ page/iaknig/williamsburgtheatreproject.

30 Arthur Knight, "Searching for the Apollo: Black Moviegoing and its Contexts in the Small-Town US South,” in Explorations in New Cinema History, 226-242.

31 Daniel Biltereyst and Philippe Meers developed the EC project. A project synopsis is found at http:// homerproject.blogs.wm.edu/projects/.

32 Jeffrey Klenotic developed the MM project. Current information on the project can be found at http:// mappingmovies.org. For more on how GIS can be used for New Cinema History, see Jeffrey Klenotic, “'Four Hours of Hootin' and Hollerin”: Moviegoing and Everyday Life Outside the Movie Palace," in Going to the Movies, 130-154, and Klenotic, "Putting Cinema History on the Map," 58-84.

33 John Sedgwick developed POPSTAT. The dataset 'Filmgoing in Portsmouth in 1934' shared with the working group is found at http://homerproject.blogs.wm.edu/projects/. See also Sedgwick's contribution to this special issue.

34 Kate Bowles, “'All the Evidence Is That Cobargo Is Slipping’: An Ecological Approach to Rural CinemaGoing,” Film Studies 10 (2007): 87-95, DOI: 10.7227/FS.10.10; Nancy Huggett, ““Everyone Was Watching!’: Strategies of Self-Presentation in Oral Histories of Cinema-Going," Studies in Australasian Cinema 1, no. 3 (2007): 261-274, DOI: 10.1386/sac.1.3.261_1. 
35 Jeffrey Klenotic, "Class Markers in the Mass Movie Audience: A Case Study in the Cultural Geography of Moviegoing, 1926-1932," The Communication Review 2, no. 4, (1998): 461-495, DOI:

10.1080/10714429809368568; Jeffrey Klenotic, “'Like Nickels in a Slot’: Children of the American Working Classes at the Neighborhood Movie House," The Velvet Light Trap: A Critical Journal of Film and Television 48 (2001): 20-33.

36 Anonymous, 'Home,' http://homerproject.blogs.wm.edu/.

37 Anonymous, 'Home.'

38 Ibid.

39 Kate Bowles at the University of Wollongong and Robert C. Allen at the University of North Carolina, Chapel Hill, spearheaded these seminars.

40 Elise D. Moore, “Towards a Common Schema in Distributed Humanities Research" (M.S. Thesis, University of North Carolina at Chapel Hill, 2010).

41 Richard Maltby, Daniel Biltereyst and Philippe Meers, "Acknowledgement," in Explorations in New Cinema History, xii.

42 The Internet Archive records the change taking place on the HoMER website sometime between May and September 2014. See, for example: https://bit.ly/2ClqTLz.

43 New Cinema History's growing entanglements with critical infrastructure studies, digital humanities, and digitised historical big data repositories are also of note. See, for example, Jeffrey Klenotic, "Mapping Infrastructures: Reflections on the Geospatial Turn in Visual Media Historiography," keynote address, "Space is the Place” conference, University of Antwerp, 2019; Deb Verhoeven, Paul Moore, Vejune Zemaityte, Skadi Loist, and Evgenia Samoilova, "Intellectual Networks and Cultural Networks: Kinomatics and the Complex Cultural Geometry of Cinema," conference paper, Digital Humanities 2019, Utrecht; Eric Hoyt, “Arclights and Zoom Lenses: Searching for Influential Exhibitors in Film History’s Big Data," in The Routledge Companion, 83-95. Biltereyst and Meers, "New Cinema History and the Comparative Mode," 20-24. Ibid., 20. Ibid.

47 Anonymous, 'Home.'

48 Daniel Biltereyst, Thunnis van Oort, and Philippe Meers, "Comparing Historical Cinema Cultures: Reflections on New Cinema History and Comparison with a Cross-National Case Study on Antwerp and Rotterdam," in The Routledge Companion, 96-111, specifically 96. 
49 Biltereyst and Meers, "New Cinema History and the Comparative Mode," 16.

50 Ibid., 13.

51 Biltereyst, Van Oort, and Meers, “Comparing Historical Cinema Cultures,” 96.

52 Clifford Geertz, The Interpretation of Cultures (New York: Basic Books, 1973), 52.

53 Geertz, The Interpretation of Cultures, 53.

54 Jeffrey Klenotic, "Roll the Credits: Gender, Geography, and the People’s History of Cinema," in The Routledge Companion, 202-216.

55 Maltby, "New Cinema Histories," 3.

56 Mary Beth Haralovich, “The Social History of Film: Heterogeneity and Mediation,” Wide Angle 8 (1986): 4-14, specifically 6.

57 Judith Thissen, “Faith, Fun and Fear in the Dutch Orthodox Protestant Milieu: Towards a Non-Cinema Centred Approach to Cinema History,” Participations: Journal of Audience \& Reception Studies 16, no. 2 (2019): 436-464; Judith Thissen, “Cinema History as Social History: Retrospect and Prospect,” in The Routledge Companion, 123-133.

58 Thissen, "Cinema History as Social History,” 125.

59 Allen, “The Place of Space," 25.

60 Richard Abel, Motor City Movie Culture 1916-1925 (Bloomington: Indiana University Press, 2020), 270.

61 Biltereyst and Meers, "New Cinema History and the Comparative Mode,” 25.

62 Springett, “Going Deeper or Flatter,"625.

63 Shaw and Sui, "Understanding the New Human Dynamics," 341-342.

64 Casey, “Smooth Spaces,” 268.

65 Springett, "Going Deeper or Flatter," 629.

66 Ibid.

67 Casey, "Smooth Spaces," 294.

68 Ibid.

69 Massey, Space, Place, and Gender, 120.

70 Ethington, “Placing the Past," 485.

71 Ibid., 486.

72 Allen, “The Place of Space,” 24.

73 Maltby and Meers, “Connections,” 18-19. 
74 Further discussion of the use of geo-social categories in historical research can be found in Elisa Ravazzoli, "The Use of Geographical Categories in Cinema Studies: An Ontological Examination," in Rural Cinema Exhibition and Audiences in a Global Context, ed. Daniela Treveri Gennari, Danielle Hipkins and Catherine O’Rawe (Cham, Switzerland: Palgrave Macmillan, 2018), 17-29.

75 Maltby and Meers, “Connections,” 21.

76 For exemplary studies in this vein of work, see Richard Abel, Menus for Movieland: Newspapers and the Emergence of American Film Culture, 1913-1916 (Oakland: University of California Press, 2013) and Paul S. Moore, “The Social Biograph: Newspapers as Archives of the Regional Mass Market for Movies," in Explorations in New Cinema History, 263-279.

77 Ethington, “Placing the Past," 485.

78 Ibid., 486.

79 Springett, “Going Deeper or Flatter,” 630.

80 David J. Bodenhamer, "Narrating Space and Place," in Deep Maps and Spatial Narratives, ed. David J. Bodenhamer, John Corrigan and Trevor M. Harris (Bloomington and Indianapolis: University of Indiana Press, 2015), 7-27, specifically 22.

81 Bodenhamer, Corrigan and Harris, Deep Maps and Spatial Narratives, 3.

82 Ibid.

83 Springett, “Going Deeper or Flatter,” 629-630.

84 Bowles, “Beyond the Boundary,” 222-223.

85 David Bodenhamer, "Beyond GIS: Geospatial Technologies and the Future of History,” in History and GIS: Epistemologies, Considerations and Reflections, ed. Alexander von Lunen and Charles Travis (Dordrecht: Springer, 2013), 1-13, specifically 11.

86 David J. Bodenhamer, "Narrating Space and Place," 18.

87 Pierluigi Ercole, Daniela Treveri Gennari and Catherine O’Rawe, “Mapping Cinema Memories: Emotional Geographies of Cinemagoing in Rome in the 1950s," Memory Studies 10, no. 1 (2017): 63-77, DOI:

10.1177/1750698016670793. The Italian Cinema Audiences project is online at http:// italiancinemaaudiences.org.

88 Silvia Dibeltulo, Sarah Culhane and Daniela Treveri Gennari, “Bridging the Digital Divide: Older Adults' Engagement with Online Cinema Heritage," Digital Scholarship in the Humanities (21 November 2019), DOI: 10.1093/llc/fqz079. The project maps can be accessed online at http://cinericordi.it/map. 
89 Springett, “Going Deeper or Flatter,” 629.

90 Bodenhamer, “Narrating Space and Place,” 18.

91 Les Roberts, “Spatial Bricolage: The Art of Poetically Making Do," Humanities 7, no. 2, 43 (2018): 2-15, specifically 1-2, DOI: 10.3390/h7020043.

92 Roberts, “Spatial Bricolage,” 3.

93 Corey Sparks, “Digital Humanities as Anamorphosis," Exemplaria 31, no. 2 (2019): 154-170, specifically 154, DOI: $10.1080 / 10412573.2019 .1581570$.

94 Kinomatics is online at http://kinomatics.com. See, for example, Alwyn Davidson, Deb Verhoeven, and Colin Arrowsmith, "Petal Diagrams: A New Technique for Mapping Historical Change in the Film Industry," International Journal of Humanities and Arts Computing 9, no. 2 (2015): 142-163, DOI: 10.3366/ ijhac.2015.0146.

95 Springett, “Going Deeper or Flatter," 629-630.

96 Ibid., 629.

97 Klenotic, Mapping Movies (2013), http://mappingmovies.unh.edu/maps.

98 The project is hosted by the University of New Hampshire and runs on a web-GIS platform known as ERMA (Environmental Resource Management Application), which was developed by the U.S. National Oceanic and Atmospheric Administration (NOAA) and the University of New Hampshire School of Earth and Ocean Sciences. It is based on open-source software, and source data is typically prepared using QGIS and/or ArcGIS. Within New Cinema History, efforts have been undertaken at HoMER conferences and workshops the past five years to provide GIS and ERMA training to the international cinema research community, and slowly data prepared and/or uploaded by other scholars is finding its way onto the site. For a review of one recent effort in this regard, see https://bit.ly/3ewCRk1.

99 John B. Krygier, "A Praxis of Public Participation GIS and Visualization," in William J. Craig, Trevor M. Harris and Daniel Weiner, Community Participation and Geographical Information Systems (London: Taylor and Francis, 2002), 330-345, specifically 330.

100 Wilson, New Lines, 140.

101 Casey, "How to Get from Space to Place," 26.

102 Wilson, New Lines, 139.

103 Bowles, "Beyond the Boundary," 225.

104 Ibid., 227.

105 Ibid., 236. 
106 Ibid., 225.

107 Ibid., 241.

108 For more on the prospects for a non-cinema centred approach to cinema history, see Thissen, "Faith, Fun and Fear.”

109 David Harvey, "On the History and Present Conditions of Geography: An Historical Materialist Manifesto," Professional Geographer 34 (1982): 1-11, specifically 7.

110 Bowles, "Beyond the Boundary," 241.

111 Bodenhamer, “Narrating Space and Place," 22.

112 Wilson, New Lines, 140.

113 Daniel Biltereyst, Richard Maltby and Philippe Meers, “Introduction: The Scope of New Cinema History,” in The Routledge Companion, 7.

114 Fishkin, “'DEEP MAPS,” 3.

115 Ibid.

116 Ibid., 13.

117 Ibid., 2-3.

118 A map of these projects can be found at http://homernetwork.org/dhp-projects/homer-projects-2/.

\section{Biography}

Jeffrey Klenotic is an Associate Professor of Communication Arts at the University of New Hampshire at Manchester. He is a founding member of the History of Moviegoing, Exhibition and Reception (HoMER) research network and the creator of Mapping Movies (http://mappingmovies.unh.edu/maps), an open-ended digital history project and interactive web-based Geographic Information System that provides geo-referenced historical data layers and GIS discovery tools for exploring cinema's social and spatial history. His essays have appeared in numerous anthologies, as well as in journals such as Senses of Cinema, Film History, Communication Review, and Velvet Light Trap. 


\section{TMG Journal for Media History}

Volume 23 No (1/2)/2020

\section{DOI}

https://dx.doi.org/10.18146/tmg.789

\section{PUBLISHER}

Netherlands Institute for Sound and Vision

\section{COPYRIGHT}

Each article is copyrighted (c) by its author(s) and is published under license from the author(s). When a paper is accepted for publication, authors will be requested to agree with the Creative Commons Attribution 4.0 International License. 